\title{
DA TEORIA À PRÁTICA DOS ESCRITÓRIOS: APROXIMAÇÕES E SINGULARIDADES PROJETUAIS EM ARQUITETURA E DESIGN
}

\section{DE LA TEORÍA A LA PRÁCTICA DE LAS OFICINAS: APROXIMACIONES Y LA SINGULARIDADES PROYECTUALES EN ARQUITECTURA Y DISEÑO}

\section{FROM THEORY TO THE PRACTICE OF THE OFFICES: PROJECT APPROXIMATION AND SINGULARITIES IN ARCHITECTURE AND DESIGN}

\section{GARCEZ, LETÍCIA V.M.}

Mestranda; PPGAU - Faculdade de Arquitetura e Urbanismo e Design - UFU; leticiavmgarcez@hotmail.com

\section{RIBEIRO, PATRÍCIA P.A.}

Doutora; profa PPGAU - Faculdade de Arquitetura e Urbanismo e Design - UFU, pparibeiro@ufu.br

\section{PEREIRA, JULIANO A.}

Doutor; prof. PPGAU-Faculdade de Arquitetura e Urbanismo e Design - UFU, pjuliano_ufu@yahoo.com.br

\section{RESUMO}

A similaridade teórica, técnica, prática e metodológica que permeia a Arquitetura e o Design se apoia no fato de ambas utilizarem seus conhecimentos para ordenar e configurar soluções projetuais. O presente artigo apresenta os resultados da pesquisa de mestrado, intitulada "Investigação sobre aproximações e singularidades nos métodos e processos de projeto em arquitetura e design: da teoria à prática dos escritórios", cujo objetivo é abordar as questões de metodologia de projeto da Arquitetura e do Design, identificando situações de aproximações e singularidades em seus contextos teóricos e práticos. Para verificar as interlocuções entre as duas áreas, especialmente na prática profissional, foram realizadas investigações de caráter qualitativo, guiadas por questionários que foram aplicados em escritórios ativos no mercado brasileiro. Tais escritórios foram selecionados e classificados em três categorias, conforme o campo de atuação: desenvolvimento de projetos de arquitetura, desenvolvimento de projetos de design e, por fim, escritórios que desenvolvem tanto projetos de arquitetura, quanto de design. Foram realizadas análises comparativas acerca dos métodos e processos de projetos utilizados a fim de verificar se na prática profissional existem realmente interlocuções dos métodos de criação dos projetos. Acredita-se que estas investigações apontam um panorama da formação do projetista, bem como o seu processo de projetar. A relevância deste estudo se afirma no fato de que, embora existam literaturas específicas sobre metodologia de projeto de Arquitetura e metodologias de Design, ambos apresentam similaridades em seus processos de projeto, sejam elas através da utilização das mesmas etapas e sequências ou das técnicas empregadas. PALAVRAS-CHAVE: metodologia de projeto em arquitetura; metodologia de projeto em design; processo de projeto; teoria e prática do projeto; análise metodológica projetual.

\section{RESUMEN}

La similitud teórica, técnica, práctica y metodológica que rodea la Arquitetura y el Diseño se apoya em el hecho de que ambas utilizan sus conocimientos para oredenar y cinfigurar soluciones de diseño. El presente artículo presenta los resultados de la investigación demaestría, titulada "Investigación sobre las aproximaciones y las singularidades en los métodos y procesos de proyecto en la arquitectura y el diseño:de la teoría a la práctica de las oficinas", cuyo objetivo es abordar las cuestiones de metodologia de proyecto de la arquitectura y del diseño, reconocendo situaciones de aproximaciones y singularidades en sus contextos teóricos y práticos. Para constatar el diálogo entre las dos áreas, especialmente en la práctica profesional, se realizaron investigaciones de carácter cualitativo, conducidas por cuestionarios que se han aplicado en las oficinas activas en el mercado brasileño. Estas oficinas fueron seleccionadas y clasificadas en tres categorías, según el campo de actuación: desarrollo de proyectos de arquitectura, desarrollo de proyectos de diseño, y por fin, oficinas que desarrollan proyectos de arquitectura ydiseño. Se realizarón análisis comparativos sobre los métodos y procesos de proyectos para verificar se en la práctica profesional existe diálogo de los métodos de creación de los proyectos.Se cree que estas investigaciones apuntan a uma visión general de la formación del desiñador, así como su proceso de diseño. La relevancia de este estudio indicó qu, aúnque existan bibliografias específicas sobre la metodología de proyectode arquitecturas y metodologías de diseño, ambos tienen similitudes en sus procesos de diseño, si utilizan los mismos pasos y las secuencias de las técnicas empleadas.

PALABRAS CLAVES: metodología de proyecto en arquitectura; metodología de proyecto en diseño; proceso de diseño; teoria e prática del proyecto; análisis metodológico proyectual.

\section{ABSTRACT}

The theoretical, technical, practical and methodological similarity that permeates Architecture and Design is supported by the fact that both use their knowledge to order and configure design solutions. The present article presents the results of the master's research, entitled "Research on approximations and singularities in the methods and project processes in Architecture and Design: from theory to practice of the offices", whose objective is to approach the questions of methodology of Architecture and of Design, identifying approximations and singularities in the theoretical and practical contexts. To verify the interlocutions between the two areas, especially in professional practice, qualitative investigations were conducted, guided by questionnaires that were applied in offices active in the Brazilian market. These offices were selected and classified into three categories, depending on the field of activity: development of architectural projects, development of design 
projects and, finally, offices that develop both architecture and design projects. Comparative analyzes were realized about the methods and project processes used in order to verify is a real interaction in the professional practice of the methods of project creation. It is believed that these investigations point to an overview of the professional training of the designer as well as his design process. The relevance of this research is affirmed in the fact that, although there are specific literature on the design methodology of Architecture and Design methodology, both have similarities in their project processes, either through the use of the same steps and sequences or the techniques used.

KEYWORDS: design methodology in architecture; project methodology in design; project process; project theory and practice; process methodological analysis.

\section{INTRODUÇÃO}

O presente estudo é parte de uma investigação maior ${ }^{1}$ que tem por objetivo detectar e estudar métodos e processos de projeto presentes nas práticas da Arquitetura e do Design, no contexto teórico e prático, identificando situações de aproximações e singularidades. A hipótese da pesquisa é que os conhecimentos em metodologias de projeto tanto em Arquitetura quanto em Design, apresentam afinidades. Muitas das interlocuções entre esses dois campos ocorrem em consequência do modo de pensar o projeto, pois o ato de projetar é comum a ambos. Na prática profissional do Brasil na contemporaneidade, as atividades de Arquitetura e Design ainda possuem interlocuções nos métodos de criação empregados nos projetos? Ambas as atividades utilizam o conhecimento teórico, técnico, prático e metodológico como condicionantes para ordenar e configurar os resultados, favorecendo soluções adequadas, pertinentes e criativas, tanto para a Arquitetura quanto para o Design (SILVA, 2009).

A pesquisa tem então como objeto de estudo os métodos e processos de projeto em Arquitetura e Design. Nesse sentido, foram selecionados cinco escritórios que desenvolvem atividades de projeto, para compreender suas práticas projetuais. Assim, os escritórios selecionados para a pesquisa seguiram os seguintes requisitos básicos: dois escritórios que trabalham com Arquitetura, dois escritórios que realizam projetos de Design e um escritório generalista que realiza projetos de Arquitetura e de Design. Estes tem trabalhos desenvolvidos recentemente (a partir dos anos de 2010) e estão localizados na região Sudeste, especificamente nos estados do Rio de Janeiro, São Paulo e Minas Gerais.

O ponto de partida da pesquisa tem como justificativa o fato de que, embora existam literaturas específicas sobre metodologia de projeto de Arquitetura e metodologias de Design, ambos apresentam similaridades em seus processos de projeto, sejam elas através da utilização das mesmas etapas e sequências ou do emprego de técnicas similares. Para avaliar o processo de projeto prático, e compará-lo ao processo de projeto de escritórios, é imprescindível investigar a literatura que aborda a metodologia de projeto, pois torna a sua compreensão mais fácil e o procedimento mais científico, consequentemente, melhora o seu gerenciamento conforme afirmam Voordt e Wegen (2013). Desta forma, pode-se diminuir os riscos de chegar a um produto final com projetos que não atendam às necessidades dos usuários (SILVA e SOUSA, 2003).

O objetivo principal da pesquisa é, portanto, verificar as aproximações e singularidades entre os processos metodológicos adotados nas práticas dos escritórios de Arquitetura e de Design, de forma a estabelecer contribuições que possam enriquecer ambos os processos. Diante disso, os objetivos específicos que circundam a pesquisa são:

- Compreender na prática dos escritórios de Arquitetura e Design as pluralidades e os distanciamentos nos métodos de criação empregados nos projetos;

- Analisar e comparar os métodos e processos de projetos de Arquitetura e Design utilizados nos escritórios, estabelecendo aproximações e singularidades com a literatura.

\section{MÉTODOS E PROCESSOS DE PROJETO}

Para Argan (2001), o processo de transferir as sequências de operações mentais em técnicas para projetar resulta em uma sequência de ações que compõem uma metodologia, pois, antes de se executar o objeto/edifício, este deve sair do campo da mente e ser investigado pelo desenho; o ato de projetar através do desenho representa o processo e é ele que conta o "como" da história. Argan ainda coloca que a "metodologia operacional é inseparável da pesquisa". O projeto deve compreender no seu traçado a consciência de todas as condições técnicas inerentes à sua realização; o objeto resultante deve assim corresponder às exigências práticas a que deve servir e, lembrando que este deve atender a um coletivo, à sociedade (ARGAN, 2001).

Para compreensão de alguns termos que são abordados ao longo da pesquisa, faz-se necessário compreender como cada um é aplicado na Arquitetura e no Design, e em qual sentido são empregados no nosso estudo. O termo MÉTODO nesta pesquisa segue o sentido de "MEIO PARA", ou seja, a técnica empregada para solucionar o problema de determinada etapa do desenvolvimento do projeto. O conjunto 
ordenado das etapas dos "meios para" compõem o PROCESSO de projeto, como "ORDEM DO FAZER". Os estudos dos "MEIOS PARA" e da "ORDEM DO FAZER", organizados de forma científica formalizam a METODOLOGIA de projeto.

\section{Estreitamento de conceitos: parâmetros de metodologia e de processo de projeto}

Os processos de projeto são estudados tanto pelas metodologias de projeto, quanto pela gestão da qualidade do projeto. Com o intuito de estabelecer um quadro-síntese, contendo os parâmetros para a análise dos escritórios selecionados para esta pesquisa. Serão apresentados, a seguir, alguns autores que discutem sobre a gestão de projeto, estabelecendo parâmetros de qualidade e indicando o mínimo de etapas que um processo de projeto deve compreender.

Existe um grande número de bibliografias que abordam esse conjunto de etapas e técnicas. Entre estas metodologias, existem aquelas com uso mais comum em Arquitetura e outras mais aplicadas ao Design. Para embasar esta discussão conceitual, os autores adotados na área da Arquitetura são: Snyder e Catanese (1984); Argan (2001); C.C.K.Kowaltowski (2011) e Voordt e Van Wegen (2013). Os autores adotados para compreensão da utilização dos termos no campo do Design são: Bonsiepe (1997), Munari (1998); Baxter (1998); Schön (2000); Löbach (2001); Coelho (2006) e Pazmino (2015).

Figura 1: Levantamento esquemático de Metodologias e de Gestão de Qualidade de Projetos.
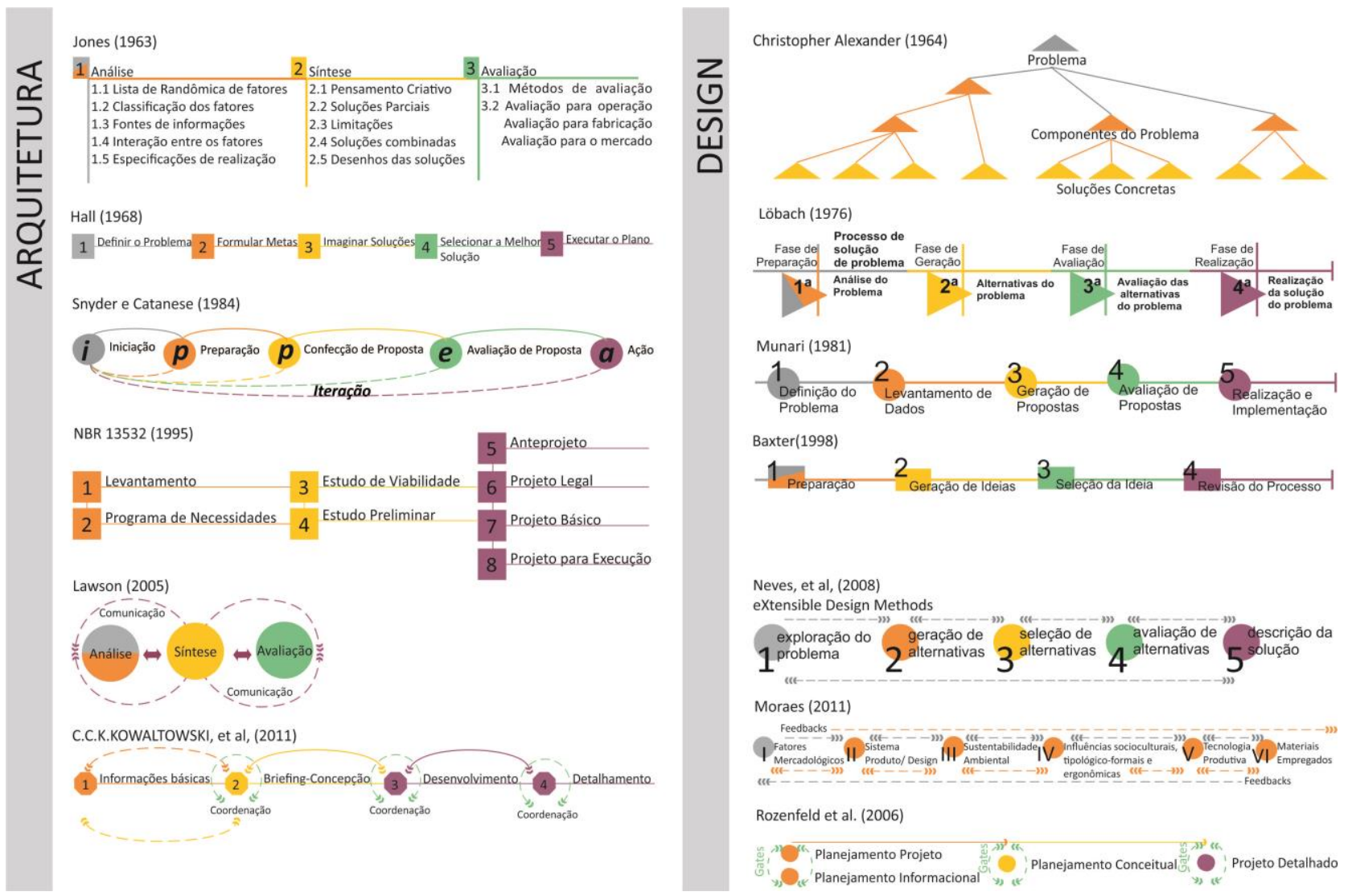

Fonte: Adaptado por autora de referências apresentadas na Figura.

Diante da análise de referências de metodologias e de gestão de projetos de Arquitetura e Design, chegouse a uma unidade metodológica que pudesse operar ambos os processos, identificando quais etapas e 0 que elas devem contemplar, conforme descrito na Figura 2. Para cada etapa metodológica, identificaram-se as ações que deveriam ser tomadas. A partir da terceira etapa, III- Criar propostas, nota-se que as linhas são cíclicas, devido aos feedbacks do usuário ou do coordenador da empresa, podendo realimentar etapas anteriores e reiniciar o processo - interação. 
Figura 2: Fluxograma de Parâmetro de Metodologias de Projeto

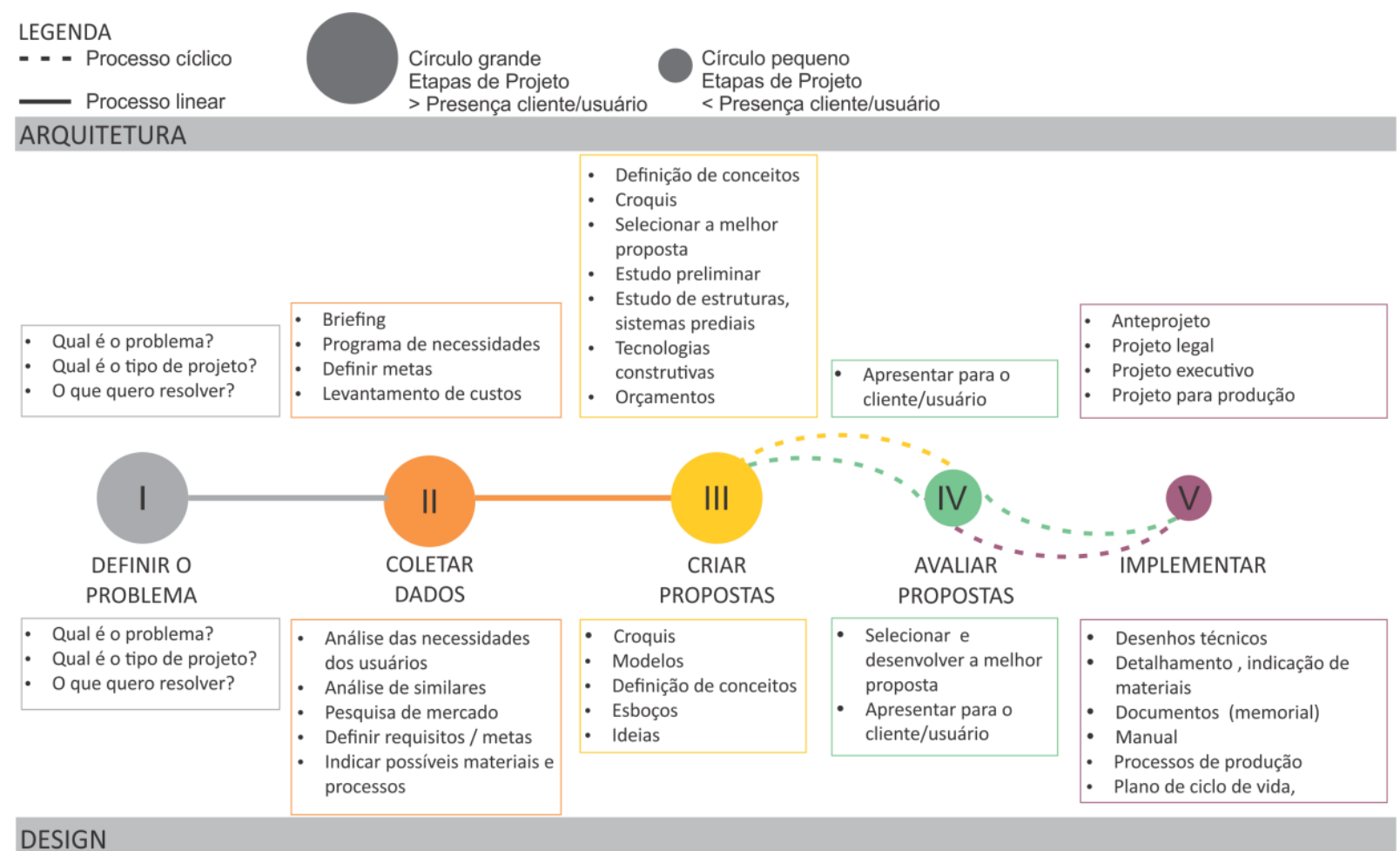

Fonte: Autora.

O Parâmetro de Metodologia de Projeto de Arquitetura e Design é uma unidade metodológica capaz de operar ambos os processos. O Parâmetro deu origem a questionamentos que motivaram a formatação de um questionário/entrevista, com questões comuns a ambos os processos. Estes foram aplicados posteriormente aos profissionais dos escritórios estudados.

\section{NA PRÁTICA: ESCRITÓRIOS² DE ARQUITETURA E DESIGN NA CONTEMPORANEIDADE}

Neste item, primeiro são apresentados os critérios e os motivos de escolha dos escritórios que viabilizaram o estudo sobre métodos e processos de projeto. No segundo momento, apresentam-se os escritórios e como estes organizam os processos de projeto em suas práticas profissionais.

\section{Critérios e motivos}

Os critérios estabelecidos para a escolha dos escritórios consideram que: estes estejam atuando ativamente no mercado, executando projetos, incentivando o uso de tecnologias inovadoras, participando de concursos de Arquitetura ou Design ou, então, que apresentem relação próxima com a academia, ou seja, que seus integrantes apresentem especialização, que atuem ou tenham atuado como professores ou colaboradores em Universidades, que ministrem cursos, palestras, agindo de modo intensivo e colaborando de forma tecnológica ou acadêmica com a profissão. A formação do responsável pelo escritório também foi considerada, sendo em Arquitetura e/ou Design, considerando que a formação tenha ocorrido a partir do final da década de 1990, entendendo que estes teriam uma formação com características de ensino mais próximas às dos dias atuais. A pesquisa buscou alcançar um panorama mais abrangente; para tanto, foram escolhidos escritórios localizados em estados diferentes, São Paulo, Rio de Janeiro e Minas Gerais, possibilitando um indicativo do cenário de produção atual nesses estados.

\section{Apresentação e análise da prática: Escritório de Arquitetura 1}

O escritório de Arquitetura $1^{3}$ fica localizado em São Paulo, SP, Brasil. A entrevista foi realiza por vídeo conferência, através de questões previamente estruturadas. A compreensão da dinâmica do processo de projeto realizado pelo arquiteto é descrito na Figura 3. 
Quadro 1: Perfil do Escritório de Arquitetura1.

\begin{tabular}{|l|l|}
\hline Local & São Paulo - SP \\
\hline Natureza dos Projetos realizados & Arquitetura (Comercial e Residência) \\
\hline Tempo de mercado & 3 anos \\
\hline Nicho de Mercado & Pessoa Jurídica e Física \\
\hline Como os projetos são & Contrato de projetos \\
comercializados & 2016 - Prêmio Ebramem/WWF de Arquitetura em Madeira \\
& 2016 - Finalista Prêmio de Arquitetura Instituto Tomie Ohtake/ Akzonobel \\
Premiações & 2014 - Menção Honrosa - Prêmio Design MCB - Luminária 1" pendente \\
& 2012 - Menção Honrosa - Prêmio Design MCB - Luminária 1" parede \\
\hline
\end{tabular}

Fonte: Autora.

Figura 3: Fluxograma Processo de Projeto Escritório de Arquitetura 1

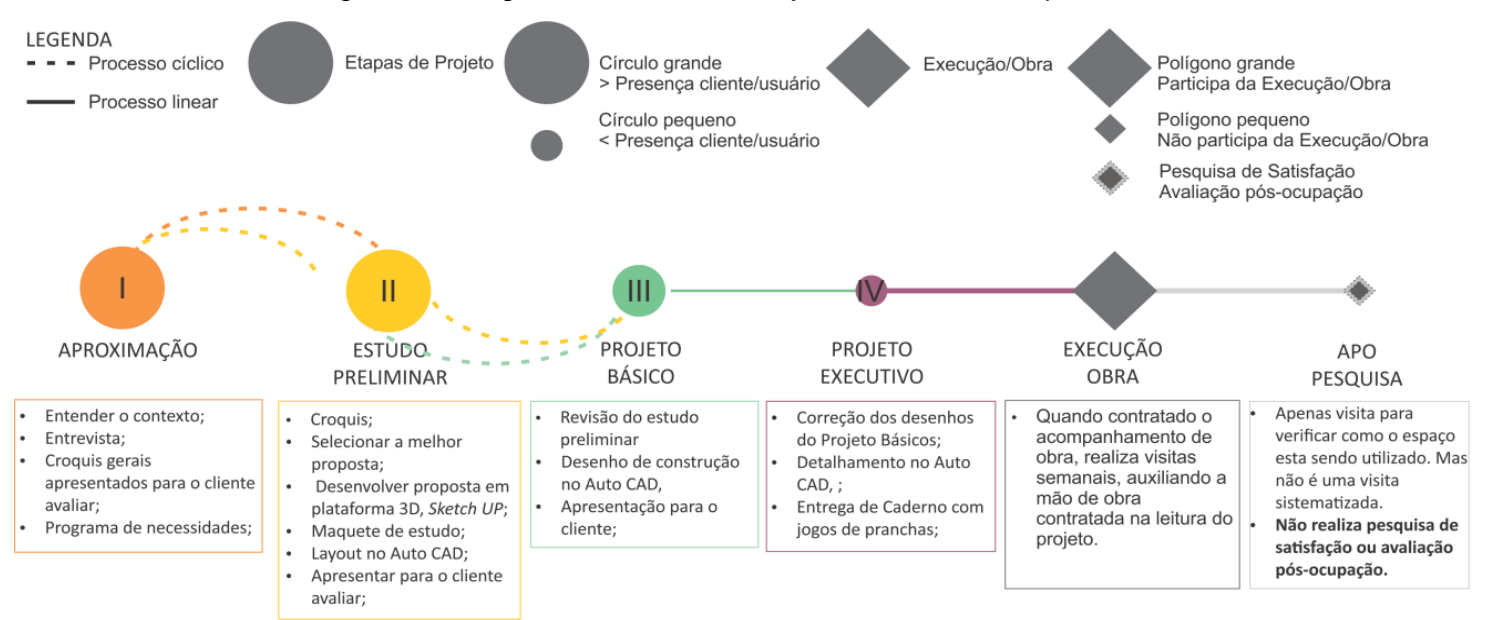

Fonte: Autora.

O processo desenvolvido pelo arquiteto é dividido em quatro etapas de projeto e uma de execução, quando o serviço de acompanhamento de obra é contratado. As etapas de projeto assim nomeadas pelo arquiteto são: Aproximação, Estudo Preliminar, Projeto Básico e Projeto Executivo.

A primeira etapa consiste em uma aproximação para entender o que é importante para aquele projeto. $O$ arquiteto realiza uma reunião, entrevista com o cliente, levantando questões que possibilitam a construção do programa de necessidades. Ainda como parte de seu processo de compreensão da problemática, o arquiteto utiliza como ferramenta o croqui. A etapa de aproximação é estendida, através dos croquis, com o intuito de viabilizar o projeto antes de se passar para a etapa seguinte. No Estudo Preliminar, segunda etapa, o arquiteto escolhe a proposta que irá atender melhor as necessidades do cliente e a desenvolve na plataforma 3D, SketchUP, também realiza o layout do projeto no Auto CAD, que serão apresentados para aprovação do cliente. Na terceira etapa, são realizadas as revisões de projeto solicitadas pelo cliente. Os desenhos corrigidos são apresentados em pranchas realizados na plataforma Auto $C A D$ e são considerados base para a construção na comunicação com os profissionais que serão contratados para executar 0 projeto. No final desta etapa, o arquiteto se reúne novamente com o cliente para apresentar os catálogos de materiais e acabamentos. Na última etapa de projeto, Projeto Executivo, são realizados a correção e o aprimoramento dos detalhamentos apresentados no Projeto Básico. O produto final dessa etapa é a entrega de um caderno de projeto, com as pranchas completas e um resumo para uso da mão de obra.

\section{Apresentação e análise da prática: Escritório de Arquitetura 2}

O Escritório de Arquitetura 2 encontra-se na cidade de Uberlândia - Minas Gerais. O escritório conta atualmente com quatro funcionários, um arquiteto responsável ${ }^{4}$ pelo escritório, uma arquiteta contratada e dois estagiários. A entrevista com o arquiteto responsável foi realizada no escritório na cidade de Uberlândia, com questões previamente estruturadas. Pode-se compreender a dinâmica do processo de projeto do escritório pelo que é apresentado na Figura 4. 
Quadro 2: Perfil do Escritório de Arquitetura 2.

\begin{tabular}{|l|l|}
\hline Local & Uberlândia - MG \\
\hline Natureza dos Projetos realizados & $\begin{array}{l}\text { Arquitetura (Comercial e Residência) } \\
\text { Hotelaria, Hospitalar e Urbanismo. }\end{array}$ \\
\hline Tempo de mercado & 14 anos \\
\hline Nicho de Mercado & Pessoa Jurídica e Física \\
\hline Como os projetos são comercializados & Contrato de projetos \\
\hline \multirow{3}{*}{ Premiações } & $\begin{array}{l}2007 \text { - Finalista (com } 3 \text { cartazes) - 22 }{ }^{\text {a }} \text { Edição, Prêmio do Cartaz, Museu } \\
\text { da Casa Brasileira. } \\
2002 \text { - } 4 \text { @ lugar - Concurso Público de Preliminares de Arquitetura e de } \\
\text { Urbanismo para Revitalização das Vias W3 Sul e W3 Norte. }\end{array}$ \\
\hline
\end{tabular}

Fonte: Autora.

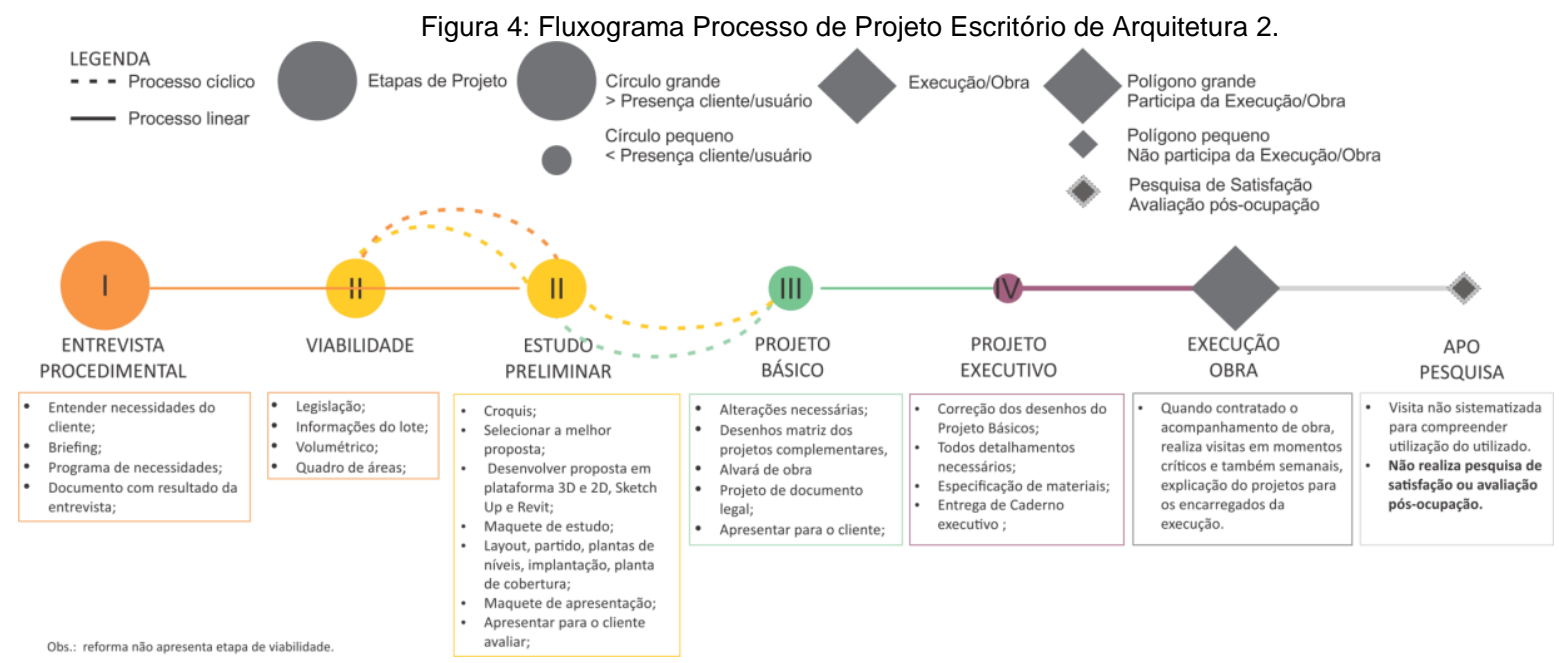

Fonte: Autora.

O Escritório de Arquitetura 2 apresenta geralmente quatro etapas de processo de projeto e uma etapa de execução. As etapas de projeto são: Entrevista Procedimental, Viabilidade (em caso de reforma esta etapa não ocorre), Estudo Preliminar, Projeto Básico, Projeto Executivo. Quanto à etapa de execução, em raros casos ela não é efetuada, conforme afirmou o arquiteto responsável. Todos os contatos com o cliente são realizados pelo arquiteto responsável, desde a primeira etapa, Entrevista Procedimental, até as demais entregas das fases de projeto.

A primeira etapa de projeto é a Entrevista Procedimental, nesta etapa ocorre uma reunião com o cliente, para que sejam levantadas as informações necessárias para o briefing, que dará origem ao programa de necessidades. Na etapa de Viabilidade são levantados os dados do terreno no qual a obra será implantada e, diante deste, realiza-se o confronto de informações da realidade do terreno com a legislação e as necessidades expressas pelo cliente na Entrevista Procedimental. No Estudo Preliminar, o arquiteto responsável formula as primeiras ideias através de croquis que, posteriormente, são levadas para uma discussão com a equipe para que as volumetrias sejam levantadas em plataforma 3D e 2D, a plataforma 3D utilizada é o SketchUP. Nesta etapa ainda são realizadas maquetes físicas de estudo para a compreensão do processo de projeto e entendimento das volumetrias; estas são então descartadas e, para aprovação do cliente, uma nova maquete de apresentação é confeccionada em escala 1/125 ou 1/200. As maquetes são realizadas em 70 a $80 \%$ dos projetos. A próxima etapa é a de Projeto Básico em que são realizadas as alterações solicitadas pelo cliente no Estudo Preliminar e são realizados os desenhos que serão a matriz para a execução da obra, ou seja, o projeto de documento legal e alvará para obra. A última etapa de projeto é a de Projeto Executivo. Ocorrem, nesta etapa, as últimas correções de projeto, assim como todos os detalhamentos e especificações de materiais necessários para a execução. Ao final dessa, um Caderno Executivo contendo todos os projetos, desde o Estudo Preliminar, são entregues ao cliente.

\section{Apresentação e análise da prática: Escritório de Design 1}

O escritório de Design $1^{5}$ fica localizado no Rio de Janeiro, RJ, Brasil. A pesquisa de processo de projeto foi realizada em duas etapas; primeiramente, foram enviadas por e-mail, em formato de questionário, as mesmas perguntas utilizadas nas demais entrevistas. Posteriormente, realizou-se uma visita ao escritório no Rio de Janeiro, para uma entrevista presencial a fim de sanar dúvidas acerca do questionário respondido e 
compreensão de sua dinâmica de trabalho. Pode-se compreender, de maneira sintética, o processo de projeto do designer pelo apresentado na Figura 5.

Quadro 3: Perfil do Escritório de Design 1.

\begin{tabular}{|c|c|}
\hline Local & Rio de Janeiro - RJ \\
\hline $\begin{array}{l}\text { Natureza dos Projetos } \\
\text { realizados }\end{array}$ & Design (mobiliário luminárias e objetos de decoração) \\
\hline Tempo de mercado & 16 anos \\
\hline Nicho de Mercado & Indústrias (Tok \& Stok, Componenti, Schuster, Novo Desenho e Maze) \\
\hline Premiações & $\begin{array}{l}2004 \text { - 10 Lugar, Prêmio Mais com Menos Madeira do SEBRAE/RO e Instituto Europeu de } \\
\text { Design2000 - 10 lugar, Concurso de Design Celina, com o sofá Céu; }\end{array}$ \\
\hline
\end{tabular}

Fonte: Autora.

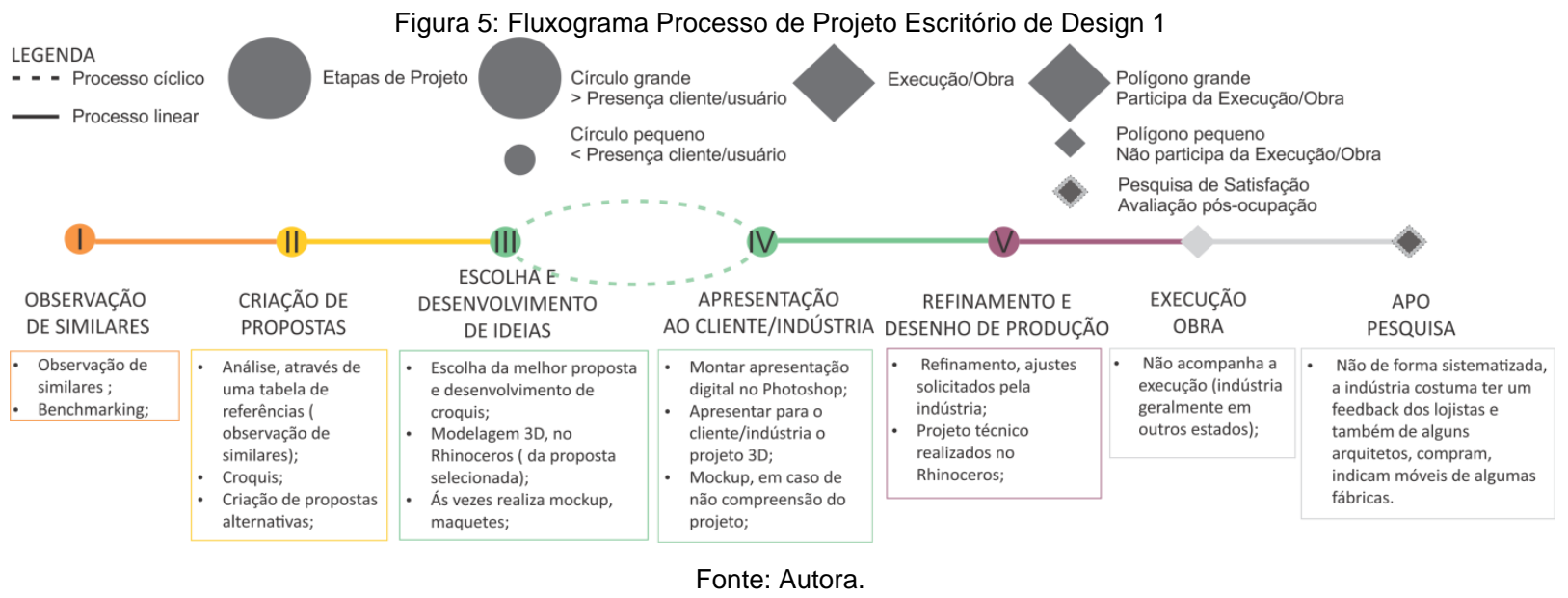

O processo de projeto do designer apresenta cinco etapas: Observação de Similares, Criação de Propostas, Escolha e Desenvolvimento de Ideias, Apresentação ao Cliente/Indústria e Refinamento e Desenho de Produção.

O designer recebe anualmente briefing de algumas indústrias que trabalham em parceria, as quais apresentam algumas diretrizes de projeto (tipo de móvel, material que será utilizado) para compor uma linha de mobiliário. A partir do recebimento do briefing, o designer começa a realizar a sua primeira etapa do processo de projeto, Observação de Similares, que consiste na busca de dados na internet ou benchmarking para verificar similares. Diante deste levantamento de dados, o designer realiza uma tabela de referências. Para a segunda etapa de projeto, Criação de Proposta, o designer analisa a tabela de similares, e cria croquis de maneira livre para compreender o contexto de criação. Nos croquis desenvolvidos, o designer procura criar um novo projeto, buscando vantagens em relação ao concorrente. $\mathrm{Na}$ etapa de Escolha e Desenvolvimento de Ideias, a proposta que apresentar maior proximidade com o briefing é desenvolvida e modelada na plataforma 3D, Rhinoceros. Para os projetos de difícil compreensão e/ou busca de simplicidade no processo de produção, o designer realiza maquetes e mockups, buscando alternativas viáveis para a produção do objeto, de acordo com a realidade da indústria. Na quarta etapa, são realizadas pranchas no Photoshop, que são apresentadas para a indústria. Partindo para última etapa de projeto, o designer realiza os ajustes de projeto solicitados pela indústria e desenvolve o desenho de produção. Nesta etapa, desenhos técnicos são realizados com alguns detalhamentos gerais e possíveis indicações de materiais e acabamentos, pois a indústria irá colaborar e interferir nos detalhes e processo de fabricação do produto. Na maioria dos projetos contratados pela indústria nacional não se realizam protótipos para estudo. O designer não participa das etapas de execução e de pesquisa de satisfação, as quais a indústria geralmente não realiza, recebendo apenas feedbacks dos lojistas que vendem seus produtos, com elogios ou reclamações dos clientes.

\section{Apresentação e análise da prática: Escritório de Design 2}

O Escritório de Design $2^{6}$ fica localizado no Rio de Janeiro, RJ, Brasil. A pesquisa de processo de projeto foi realizada através de uma visita em seu escritório no Rio de Janeiro, para uma entrevista presencial. Foram utilizadas as mesmas questões aplicadas nos demais escritórios. O processo de projeto do designer pode ser observado na Figura 6. 
Quadro 4: Perfil do Escritório de Design 2.

\begin{tabular}{|l|l|}
\hline Local & Rio de Janeiro - RJ \\
\hline Natureza dos Projetos realizados & Design (mobiliário luminárias e objetos de decoração) \\
\hline Tempo de mercado & 15 anos \\
\hline Nicho de Mercado & Indústrias (Oppa, Schuster, E L O N - Móveis de Design) \\
\hline & 2017 - Prêmio Salão Design \\
& 2015 -29 Prêmio Design Museu da Casa Brasileira \\
Premiações & 2014 / 2013 - Exposição Rio+Design \\
& 2013 - Exposição Rio+Design Milão \\
& 2012 Prêmio ABILUX de design de luminárias \\
\hline
\end{tabular}

Fonte: Autora.

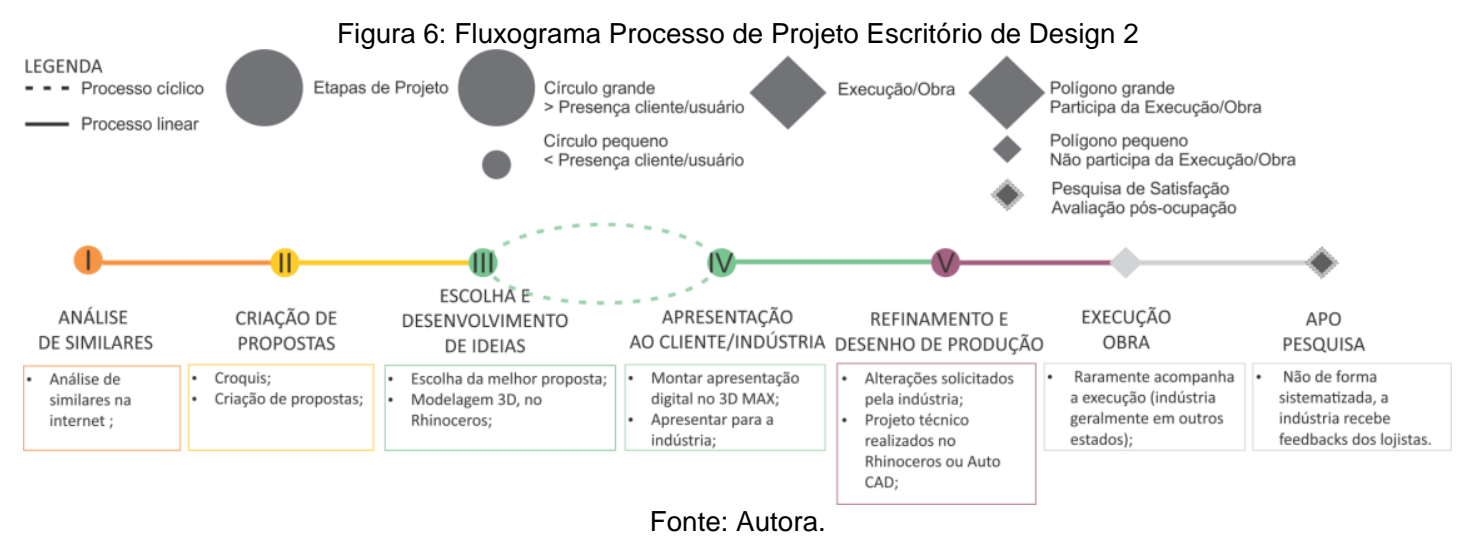

O processo de projeto do designer se divide em cinco etapas: Análise de Similares, Criação de Propostas, Escolha e Modelagem da Ideia, Apresentação ao Cliente/Indústria e Desenho de Produção.

O designer trabalha em parceria com algumas indústrias das quais recebe, anualmente, briefings de projetos a ser desenvolvidos. O briefing solicita a composição de linhas de mobiliário, conforme as diretrizes nele contida (público alvo, tecnologia a ser utilizada na produção). Após sua análise o designer realiza a Análise de Similares, sua primeira etapa do processo de projeto, através de buscas na Internet. Para a Criação de Proposta o designer analisa os similares pesquisados e realiza croquis de maneira livre para obtenção das primeiras ideias que, na etapa seguinte - Escolha e Desenvolvimento de Ideias, serão desenvolvidas na plataforma 3D, Rhinoceros. Após a modelagem e maior definição, o projeto é apresentado para a indústria; em alguns casos as indústrias apresentam o desenho 3D para os lojistas avaliarem. Na quarta etapa, são realizadas pranchas de apresentação digital no $3 D M A X$, em caso de desaprovação do projeto, estes são alterados e reapresentados. Na etapa de Desenho de Produção, o designer realiza as últimas alterações de projeto solicitadas pela indústria, e elabora os desenhos técnicos para a produção, no Rhinoceros, e às vezes no Auto $C A D$. O desenho apresenta detalhes gerais, pois a indústria define alguns materiais e detalhes conforme seu maquinário. Raramente o designer acompanha a execução de protótipos. A indústria não realiza pesquisa de satisfação, recebendo apenas feedbacks dos lojistas que vendem seus produtos.

\section{Apresentação e análise da prática: Escritório de Arquitetura e Design}

O escritório de Arquitetura e Design ${ }^{7}$ está localizado na cidade São Paulo, SP, Brasil. O escritório realiza projetos tanto em escala arquitetônica como nas diversas abrangências do Design (gráfico, interiores, mobiliário). O escritório tem oito funcionários, quatro arquitetos, uma designer e três estagiárias. A pesquisa de processo de projeto foi realizada em duas etapas. Primeiramente, foram enviadas por e-mail as perguntas utilizadas nas demais entrevistas. Posteriormente, realizou-se uma visita em seu escritório em São Paulo, para uma entrevista presencial a fim de sanar dúvidas sobre o questionário e melhor compreensão de sua dinâmica de trabalho. Pode-se compreender o processo de projeto do escritório pelo sintetizado na Figura 7.

Quadro 5: Perfil do Escritório de Arquitetura e Design

\begin{tabular}{|l|l|}
\hline Local & São Paulo - SP \\
\hline Natureza dos Projetos realizados & Arquitetura, Design de Interiores, Gráfico e Mobiliário \\
\hline Tamanho da Equipe & 8 \\
\hline Tempo de mercado & 4 anos \\
\hline Nicho de Mercado & Pessoa Jurídica e Física \\
\hline $\begin{array}{l}\text { Como os projetos são } \\
\text { comercializados }\end{array}$ & $\begin{array}{l}\text { Contrato de : projetos, gerenciamento de obra, Design e produção de mobiliário / Loja } \\
\text { Mono Design }\end{array}$ \\
\hline
\end{tabular}

Fonte: Autora. 
Figura 7: Fluxograma do Processo de Projeto Escritório de Arquitetura e Design.

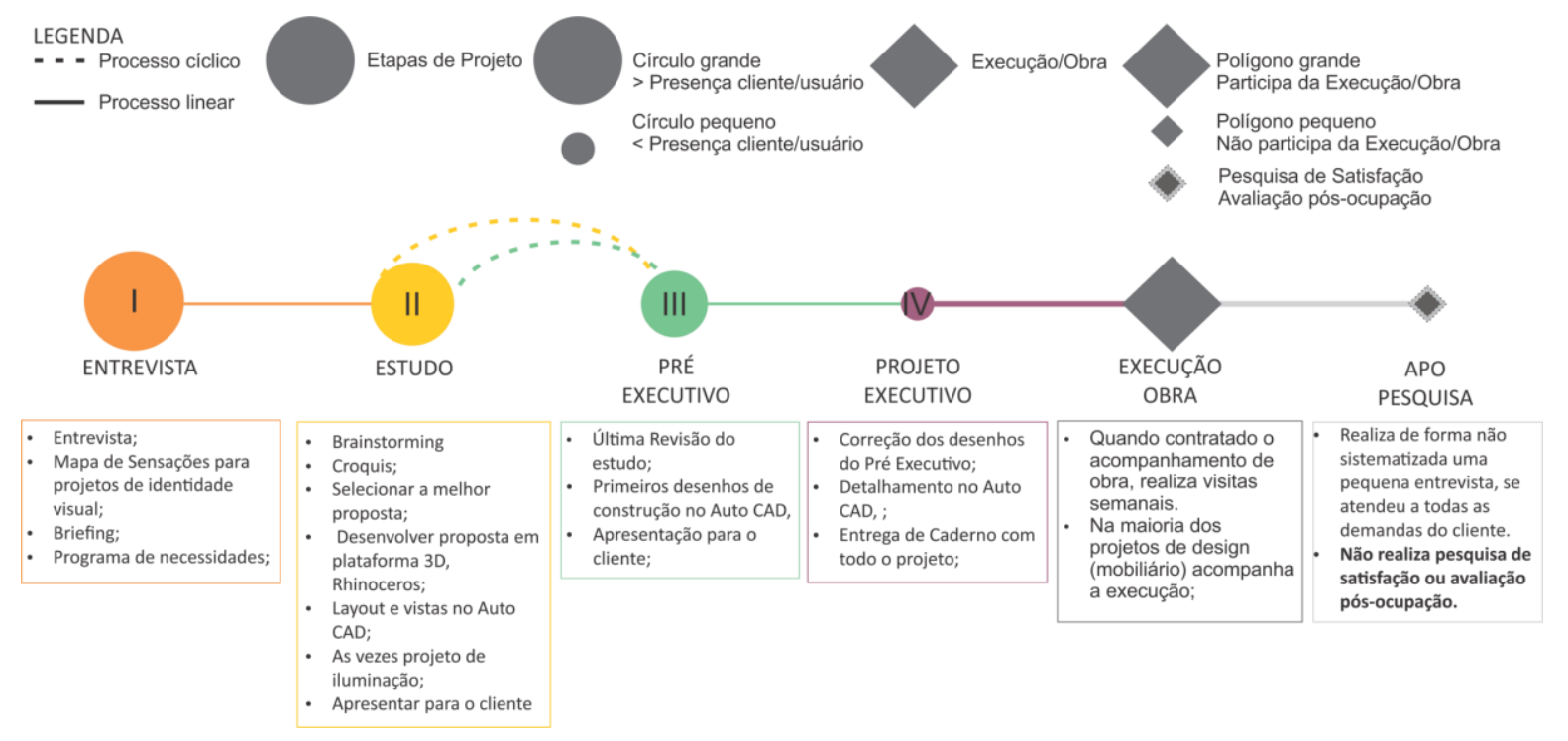

Fonte: Autora.

O processo de projeto do escritório é estruturado em quatro etapas de projeto e uma de execução. As etapas de projeto são: Entrevista, Estudo, Pré-Executivo e Projeto Executivo.

$O$ processo se inicia por uma entrevista realizada pelo arquiteto fundador e também pela outra arquiteta titular e, depois, o projeto é direcionado para uma equipe de funcionários (arquitetos/designer/estagiários) que apresentem maior afinidade com o projeto. Em casos de projetos comerciais em que são realizados Projetos de Interiores e de Identidade Visual, o escritório utiliza uma ferramenta desenvolvida por eles para as entrevistas, o Mapa de Sensações. Este consiste em um layout do espaço a ser projetado pelo escritório, em que o cliente identifica nos respectivos ambientes, a sensação que este deverá transmitir. A partir dos dados levantados nas entrevistas, o escritório elabora o briefing, que dará origem ao programa de necessidades. Para etapa de Estudo, primeiramente é realizada um reunião para o brainstorming levantamento de ideias. Desta dinâmica participam o responsável do escritório e a equipe que irá executar o projeto. Após o levantamento de ideias, são realizados croquis, dentre os quais a melhor proposta posteriormente será desenvolvida pela equipe de projeto. Ao ser definida esta é desenvolvida primeiramente em desenhos manuais, lápis e papel, em seguida em plataforma 3D, Rhinoceros e também 2D, AutoCAD. São realizadas pranchas em PDF - Portable Document Format, que são apresentadas para o cliente. $\mathrm{Na}$ terceira etapa, são gerados os primeiros desenhos para a construção/execução juntamente com algumas pré-definições de revestimentos e acabamentos. Estes desenhos são apresentados para a aprovação do cliente. Na última etapa de projeto, Projeto Executivo realizam-se as revisões solicitadas pelo cliente no Projeto Pré-Executivo e são finalizados todos os desenhos técnicos com detalhamentos e indicações de materiais. Concluídos os desenhos compõem um caderno de projeto, com todas as pranchas desde a ideia inicial, da etapa de Estudo até o final, Projeto Executivo, que é entregue ao cliente, juntamente com a apresentação 3D.

Após a análise em separado da dinâmica que compõe o processo de projeto dos escritórios, realizou-se um comparativo entre estes e o Fluxograma de Parâmetro de Metodologias de Projeto (Figura 2). A seguir, é feita uma discussão transversal entre os métodos de projeto dos escritórios.

\section{RESULTADOS: DISCUSSÃO TRANSVERSAL, APROXIMAÇÕES E SINGULARIDADES ENTRE MÉTODOS E PROCESSOS DE PROJETO NA ARQUITETURA E NO DESIGN}

A análise comparativa realizada possibilita, de certo modo, um panorama dos processos de projetos dos escritórios, em que, de maneira geral, nota-se uma estruturação dos processos de projeto em quatro etapas definidas. Apesar de serem denominadas de forma diferente por cada escritório, as atividades desenvolvidas são semelhantes, porém, apresentando maior ou menor profundidade de ações e técnicas distintas adotadas nos processos projetuais.

O comparativo entre os processos de projeto dos escritórios de Arquitetura e de Design e o Parâmetro de Metodologias de Projeto estabelecido anteriormente é sintetizado na Figura 8. 
Figura 8: Discussão Transversal: Prática Projetual dos Escritórios X Fluxograma de Parâmetro de Metodologias. LEGENDA

- Processo cíclico

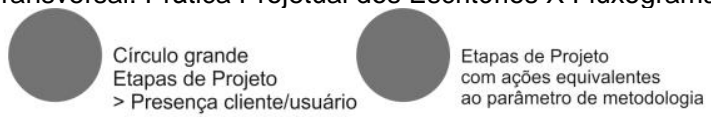

- Processo linear Etapas de Projeto ao parâmetro de metodologia
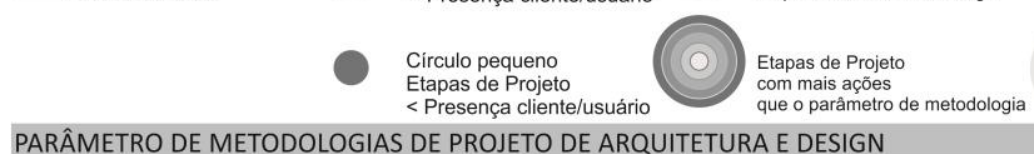

Etapas de Projeto que o parâmetro de metodologia

PARÂMETRO DE METODOLOGIAS DE PROJETO DE ARQUITETURA E DESIGN
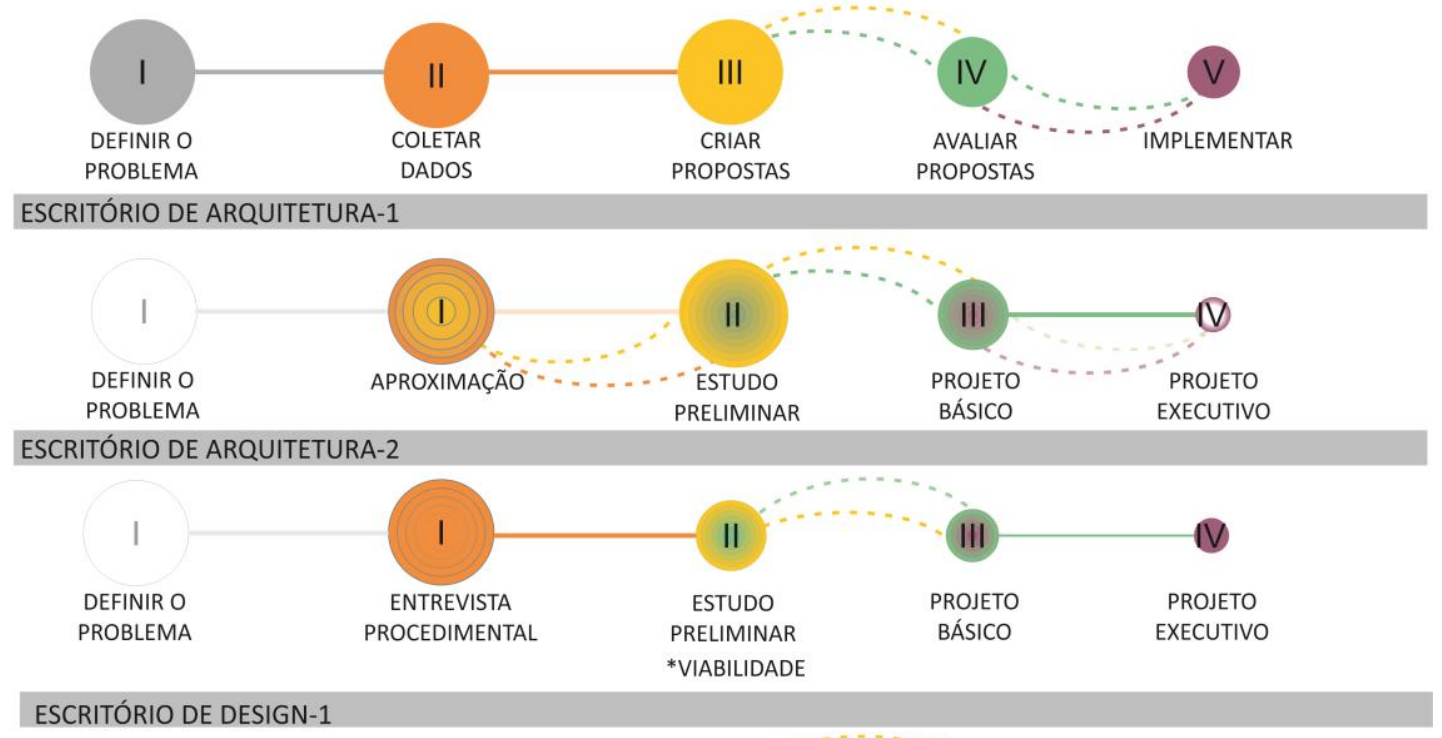

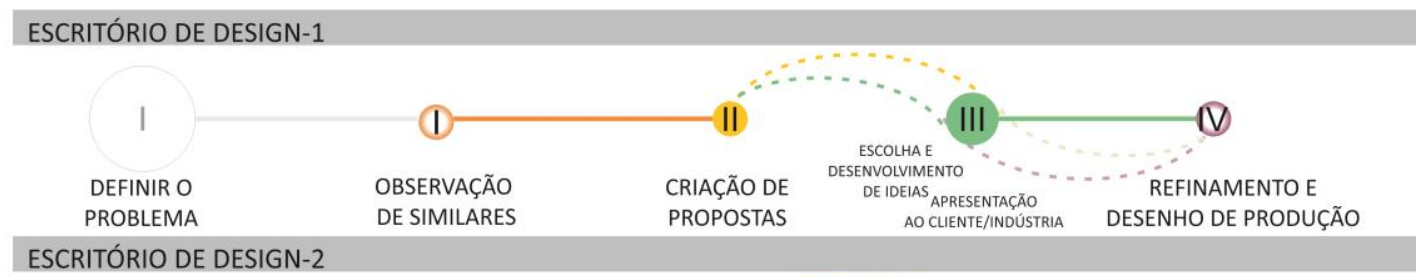

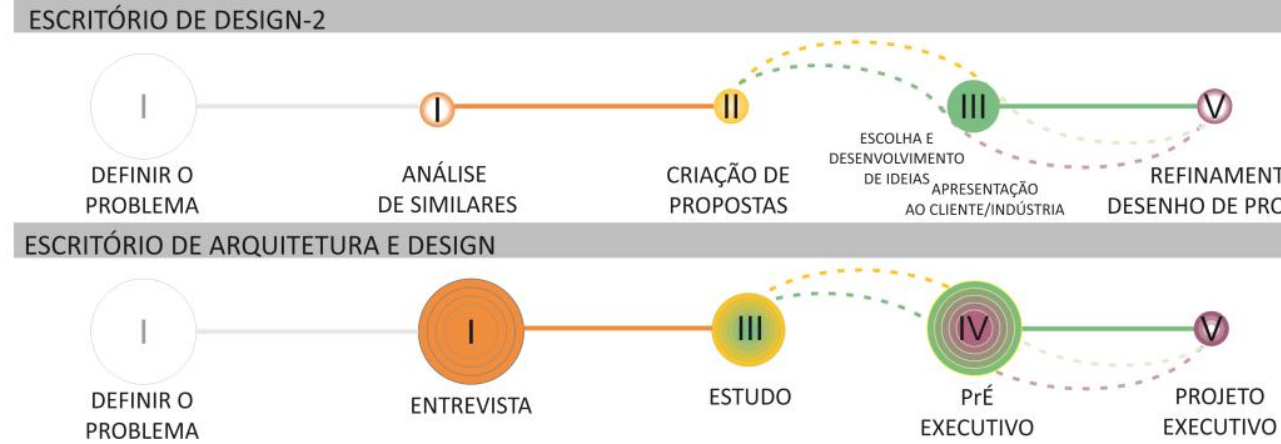

Fonte: Autora.

\section{I- Definir o problema | Início de Projeto}

Percebe-se que esta etapa, indicada nas metodologias de projeto acima estudadas, não aparecem como uma etapa definida na prática dos escritórios aqui analisados. Apesar de os Escritórios de Arquitetura 1 e 2 e o Escritório de Arquitetura e Design apresentarem relação estreita com o usuário, estes não realizam separadamente esta etapa. Ação esta que também não ocorre nos escritórios de Design 1 e 2, pela ausência de contato do designer com o usuário.

A definição do problema ocorre no percurso do processo, às vezes na segunda etapa (II - Coletar Dados). Esse processo se inicia por um problema definido pelo cliente, que muitas vezes não é discutido pelo escritório contratado. Porém, conforme Kowaltowski et al. (2011) e Lawson (2011), o arquiteto deve buscar a solução para o problema, identificando as problemáticas fundamentais para auxiliar na determinação da resposta projetual, mas não em definir o problema de projeto.

Esta ausência de definição do problema, assim como a ausência do projetista na identificação, pode ocasionar interpretações equivocadas, gerando indefinições e retrocessos no processo de projeto. 


\section{II - Coleta de Dados}

O Escritório de Arquitetura 1 apresenta um acúmulo de ações e a presença do usuário é expressiva nesta etapa. Percebe-se que a definição do problema acontece juntamente com a coleta de dados. Nesta etapa também são gerados os primeiros croquis, apresentados para o cliente, causando iteração no processo, que no Parâmetro de Metodologia é linear. Esta dinâmica pode motivar definições equivocadas, pois conforme Voordt e Wegen (2013) é importante apresentar a fase de coleta de informações separada da fase de projeto. Para o Escritório de Arquitetura 2 e o Escritório de Arquitetura e Design, nota-se que há grande participação do usuário/cliente nesta etapa, interação está em consequência da busca de solução das problemáticas que norteiam o programa de necessidades.

Para esta etapa conclui-se ainda que os escritórios que apresentam contato direto com o cliente/usuário (Escritório de Arquitetura 1 e 2, Escritório de Arquitetura e Design) a ferramenta em comum utilizada para levantar os dados é a entrevista, com algumas nuances de diferenças entre os escritórios. Nota-se também a importância dessa etapa para o Escritório de Arquitetura e Design, que em projetos de design de interiores e de identidade visual utilizam o "Mapa de Sensações" (ferramenta desenvolvida pelo próprio escritório, já relatada anteriormente), que facilita a interação e comunicação do projetista com o cliente, auxiliando no processo de solução do problema, além de possibilitar maior profundidade e reflexão por parte do projetista. Interação essa que se faz bastante presente nas metodologias centradas no usuário, que buscam de forma aprofundada a compressão das necessidades e desejos dos usuários, a fim de que os produtos venham atender de maneira funcional e também psicológica.

A análise demonstra que, na prática projetual, os Escritórios de Design 1 e 2 não apresentam toda a etapa de coleta de dados e o contato com o usuário, pois este procedimento é realizado pela indústria. Diante desta sistemática, os escritórios realizam apenas as ações de análise de similares, pesquisa de concorrentes e análise de tecnologia a ser utilizada no processo de produção. A pesquisa sobre a tecnologia a ser utilizada é realizada pelo Escritório de Design 1 de forma mais aprofundada, pois irá interferir diretamente na etapa seguinte (III - Criar Propostas).

\section{III - Criar propostas}

$\mathrm{Na}$ etapa de criação de propostas, ocorrem dinâmicas diferentes entre os escritórios, apesar de todos utilizarem a mesma técnica, o croqui, para iniciarem a geração de propostas. Outro método adotado no processo de criação é a maquete física, ferramenta utilizada por todos os Escritórios entrevistados, exceto pelo escritório de Design 2. A maquete facilita a compreensão volumétrica, a espacialidade e, também é ferramenta de pesquisa para compreensão do processo de produção.

O Escritório de Arquitetura 1, por já ter iniciado os croquis na etapa anterior, parte de suas definições já foram tomadas, assim, nesta etapa há apenas a seleção da ideia a ser desenvolvida. A geração de propostas não é explorada pelo arquiteto nesta etapa, isto causa menor quantidade de ações em referência ao padrão estabelecido pela metodologia. Por outro lado, o arquiteto antecipa ações da etapa subsequente, como a apresentação do projeto para avaliação do cliente.

Os escritórios de Design 1 e 2, e o Escritório de Arquitetura 1 trabalham individualmente, inviabilizando assim ações de brainstorming e discussão. Nos escritórios que trabalham com equipe, Escritórios de Arquitetura 2 e Escritório de Arquitetura e Design, dinâmica semelhante é realizada através de discussão. Porém, o que diferencia é que o coordenador do Escritório de Arquitetura 2 concebe as primeiras propostas individualmente, para posteriormente levá-las para discussão com os demais da equipe.

Nesta etapa de projeto, os Escritórios de Design 1 e 2, realizam ações equivalentes ao parâmetro de metodologia, como croquis, maquetes e definições de conceitos, porém, sem a presença do usuário.

Faz-se importante mostrar a relevância desta etapa do processo para o escritório de Arquitetura e Design, nos projetos de mobiliário, ocasionando mudanças no processo e o aproximando de certa forma com o modelo Metaprojetual, colocado por Moraes (2011), em que primeiro tem-se que considerar a tecnologia produtiva e as matérias-primas, os fatores sociais e mercadológicos correlacionados, para seguidamente atentar-se para a coerência estético-formal.

\section{IV- Avaliar propostas}

Percebe-se que nos Escritórios de Arquitetura 1 e 2 e Escritório de Arquitetura e Design o projeto está na segunda avaliação, pois o projeto foi avaliado pelo usuário no final do Estudo Preliminar e será também agora, nesta etapa, avaliado o Anteprojeto, entendido pelos Escritórios de Arquitetura 1 e 2, como Projeto Básico e pelo Escritório de Arquitetura e Design como Pré-Executivo. Fato que demonstra maior envolvimento com os clientes/usuários por meio de feedbacks, nas primeiras etapas do processo, tornando o processo de projetar cíclico e interativo. Aproximando-se das metodologias centradas no usuário, como as 
metodologias de Snynder e Catanese (1984) e a XDM, Neves (2008). Porém, essa interação com o usuário não volta a ocorrer na etapa subsequente.

Ambos os Escritórios de Design 1 e 2 dividem esta etapa em dois momentos (escolha e desenvolvimento de ideias; apresentação para o cliente/indústria), mas, em consequência das ações equivalerem às atividades da etapa quatro (IV - Avaliar Propostas), estas ações foram unificadas em uma única etapa. A avaliação deveria ocorrer pela indústria e também pelo usuário para se assemelhar com o Parâmetro de Metodologia.

\section{V- Implementar}

Identifica-se que os Escritórios de Arquitetura 1 e 2, e o Escritório de Arquitetura e Design, realizam menor quantidade de ações do que as identificadas no Parâmetro de Metodologia, produzindo os desenhos referentes ao Projeto Executivo, o qual é realizado em diferentes plataforma digital 2D, a caráter de afinidade do escritório. O usuário interage minimamente com o projetista apenas na entrega do caderno de projeto (conjunto de desenhos que apresenta todos os detalhamentos necessários assim como definições de materiais, buscando melhor comunicação com a mão de obra que irá executar o projeto), fato esse que torna o processo linear e não cíclico, conforme o Padrão de Metodologia. Ainda para esses escritórios, o seu processo de projeto se estende no acompanhamento de obra/execução do projeto.

Os Escritórios de Design 1 e 2, por sua vez, realizam os desenhos técnicos gerais, pois as definições de materiais e processos são efetuadas pela indústria. Não ocorre muita interação do projetista com a indústria, prejudicando soluções projetuais e tecnológicas que poderiam ser pesquisadas e implementadas através da presença do designer na produção e no investimento em protótipos. Distanciando da ideia de Metaprojeto, que busca a solução de problemas complexos de Design, abrangendo estudos estruturais, estético-formais e funcionais, com intuito de responder a anseios materiais, sociais, econômico, político e psicológicas dos usuários.

Apesar das literaturas consultadas enfatizarem a importância da pesquisa de pós-ocupação na Arquitetura, para a compreensão das necessidades e desejos dos usuários, nenhum dos escritórios estudados destacou essa prática como uma etapa inerente ao processo. Fato que se repete nos Escritórios de Design, em que a pesquisa de satisfação acontece apenas por feedbacks dos lojistas, através de elogios ou reclamações dos clientes sobre algum produto, inviabilizando, assim, um processo cíclico.

\section{CONSIDERAÇÕES FINAIS}

Nota-se que atualmente as interlocuções projetuais podem ser identificadas nos escritórios selecionados nesta pesquisa, em consequência das mesmas etapas e sequências nos processos de projetos, ou dos métodos empregados para solucionar as problemáticas projetuais.

Pode-se considerar que a principal contribuição desta pesquisa para o meio acadêmico e também profissional, é a identificação da apresentação, em todos os escritórios, de um processo de projeto definido, com divisão de etapas, organizando e estabelecendo uma linha de raciocínio para os projetos, apesar das peculiaridades. Entende-se que os estudos de metodologia em meio acadêmico apresentam reflexos em suas práticas profissionais. Apesar de nenhum dos escritórios mencionarem adotar referências literárias para realizar seus processos de projetos, nota-se que estes ainda estão muito subjugados a modelos padrão. Em que apenas um dos escritórios consultados (Escritório de Arquitetura e Design), identifica-se a busca por ferramentas, métodos para facilitar a comunicação e a interação com o usuário, para além de responder o problema de projeto com uma funcionalidade, mas também ligado a fatores psicológicos.

Via de regra, as semelhanças se fazem pelo cumprimento de algumas etapas, que apesar de cada escritório as denominar de diferentes formas, os métodos e caminhos tomados para solucionar os problemas apresentam proximidades, ainda que existam literaturas específicas de metodologia de projeto tanto para Arquitetura como para Design.

A principal diferença que se pode constatar, nos processos dos escritórios utilizados como objetos de estudo, é a presença do usuário. Apesar de ser considerada a importância da presença do usuário, este não colabora de modo efetivo, interferindo no processo de projeto dos escritórios que trabalham especificamente com Design. Fato esse que acaba inviabilizando a interação no processo, ou seja, não o torna cíclico. O usuário para quem o produto/serviço é destinado não tem "voz ativa" sendo condicionado a aceitar as ofertas de mercado que lhe são demandadas. A postura adotada por estes escritórios revela como estes profissionais ficam submetidos às indústrias, que visam um consumo de massa, em prol da lucratividade. Isto revela que as metodologias de projeto contemporâneas, em que se buscam projetos colaborativos e que utilizem referências culturas e sociais, são uma realidade distante. Ainda, faz-se importante ressaltar a displicência tanto por parte das indústrias, que realizam os protótipos sem a presença 
do projetista e, também por parte dos projetistas, por não se posicionarem diante dessa atitude das indústrias. A participação do projetista no momento da execução do protótipo pode resultar em soluções técnicas, com maior coerência projetual.

Outra questão que pode ser apontada ao se comparar a literatura com a prática, é a inexistência de uma etapa específica para a definição do problema, definição esta que acaba ocorrendo no percurso do processo, nos escritórios que apresentam a presença do usuário (Escritório de Arquitetura 1 e 2 e Escritório de Arquitetura e Design), ainda que estes não participem ativamente do processo de projeto, revelando que na atualidade esta definição é compreendida ao se buscar entender as necessidades, expectativas, desejos e aspirações do usuário em suas questões simbólicas e subjetivas. O que releva a importância da relação próxima com o usuário. Pois é dessa relação que se identificará as condicionantes para o projeto.

A relação de proximidade com usuário deve também ser repensada no ensino acadêmico em que, nas experiências de projeto em sala de aula, o usuário é simulado, o que limita a existência de feedback e a reflexão teórica/prática do uso de metodologias contemporâneas. O que acabada retomando os processos de projetos lineares, em que se projeta para um usuário ideal. Chega-se à conclusão de que é importante que, em alguma etapa da formação acadêmica, o estudante possa experimentar e desenvolver projetos com a adoção de um usuário real para que possam compreender melhor os métodos existentes e melhor se prepararem para enfrentar o ofício de sua profissão e responder às demandas contemporâneas de projeto.

Uma das grandes contribuições diante das mudanças contemporâneas, conforme Almeida et al. (2016), são as tecnologias digitais, por serem interativas e possibilitarem a inclusão social em seus vários aspectos. Esta tecnologia, quando utilizada pelo Escritório de Arquitetura e Design, que faz uso de Design Aberto ${ }^{8}$, gera uma aproximação entre o escritório e as metodologias contemporâneas enfatizadas por Almeida et al. (2016) e Moraes (2011). Estas tratam do conceito de Metaprojeto, pois considera, na concepção do projeto, os processos produtivos, materiais, fabricação e os processos de distribuição, o que pode gerar também maior competitividade, ampliação do ciclo de vida de produtos, inovação nos processos e no desenvolvimento de soluções. Afinal, entende-se que os estudos por prototipagem digital são mais ágeis e possibilitam correções projetuais de maneira mais rápida.

Vê-se que a metodologia XDM não aparece claramente na prática dos escritórios, pois são mais aplicadas nas práticas ligadas a comunidades sociais e a ações envolvidas com universidades. Normalmente são ações sem fins lucrativos, o que não foi objeto de estudo desta pesquisa.

Faz-se importante ressaltar que a pesquisa apresentou limitação de prazo, não possibilitando uma grande amostragem de escritórios. Conseguiu-se também obter um indicativo do cenário da produção atual, apesar do tamanho da amostra, ao se considerar a natureza qualitativa do estudo e os critérios na seleção dos entrevistados, esta se justifica. Possivelmente, outros padrões de processos projetuais poderiam ter sido visualizados, caso o número de participantes fosse maior. Outra limitação do estudo foi o não acompanhamento da prática do projeto pelo pesquisador nos escritórios, ou seja, a pesquisa baseia-se em como os profissionais percebem o seu desenvolvimento de projeto e dos documentos utilizados pelos mesmos. Provavelmente, ao observar o processo prático, novas questões seriam levantadas.

\section{AGRADECIMENTOS}

A FAPEMIG pelo apoio e concessão de bolsa de mestrado desenvolvido no PPGAU - FAUeD - UFU.

\section{REFERÊNCIAS}

ALEXANDER, Christopher. Ensayo sobre la sintesis de la forma. 5. ed. Buenos Aires: Infinito, 1986. 219 p.

ALMEIDA, Mariana Dias de et al. Transversalidades no Design Contemporâneo: Novos sujeitos em busca da inclusão. In: PASCHOARELLI, Luiz Carlos; SALCEDO, Rosio Fernández Baca. Design, Arquitetura e Urbanismo: Transversalidades. Bauru: Canal6, 2016. Cap. 8. p. 103-114.

ARGAN G. C. Projeto e destino. São Paulo: Ática, 2001.

ASSOCIAÇÃO BRASILEIRA DE NORMAS TÉCNICAS. NBR 13531: Elaboração de projetos de edificações - Atividades técnicas. Rio de Janeiro: Copyrigh, 1995. 10 p.

BAXTER, M. R. Projeto de Produto: Guia Prático para o Design de Novos Produtos. 2. Ed. São Paulo: Editora Blücher, 1998. 
BOMFIM, Gustavo Amarante. Morfologia dos objetos de uso: uma contribuição para o desenvolvimento de uma teoria do design. In: COUTO, Rita Maria de Souza; FARBIAZ, Jackeline de Lima; NOVAES, Luiza. Gustavo Amarante Bomfim: uma coletânea. Rio de Janeiro: Rio Books, 2014d, p. 23-33.

BONSIEPE, Gui. A tecnologia da tecnologia. São Paulo: Ed. Ed. Blucher, 1983.

BONSIEPE, Gui. Design do material ao digital. Santa Catarina: FIESC/IEL, 1997. 192 p.

BONSIEPE, Gui. Design, cultura e sociedade. São Paulo: Blucher, 2011.

BÜRDEK, Bernhard E. DESIGN: História, Teoria e Prática do Design de Produtos. São Paulo: Ed. Blucher, 2006.

C.C.K.KOWALTOWSKI, Doris et al. O processo de projeto em arquitetura da teoria à tecnologia. São Paulo: Oficina de Textos, 2011. $504 \mathrm{p}$.

CÂMARA, J., et al (Argentina). A GESTÃO DO DESIGN NA CONCEPÇÃO DE NOVOS PRODUTOS E A DIFERENCIAÇÃO MERCADOLOGICA. Actas de Diseño: II Encuentro Latinoamericano de Diseño "Diseño en Palermo", Buenos Aires, v. 3, n. 2, p.84-87, jul. $2007 . \quad$ Disponível em: <http://fido.palermo.edu/servicios_dyc/publicacionesdc/archivos/11_libro.pdf>. Acesso em: 13 abr. 2015.

CARDOSO, Rafael. Uma Introdução a História do Design. 3. ed. São Paulo: Blucher, 2008.

CIPINIUK, Alberto; PORTINARI, Denise B. Sobre métodos de Design. In: COELHO, Luiz Antonio L. (Org.). Design Método. Rio de Janeiro; Ed. PUC-Rio; Teresópolis: Novas Ideiais, 2006, p. 17-38.

COELHO, Luiz Antônio L. Design método. Teresópolis: Novas Ideias, 2006.

FABRíCIO, Márcio Minto; ORNSTEIN, Sheila Walbe. Qualidade no Projeto de Edifícios. São Carlos: Rima Editora, Antac, 2010. 274 p.

GIL, Antonio Carlos. Métodos e Técnicas de Pesquisa Social. 6. ed. São Paulo: Atlas, 2008.

GUIMARÃES, Ana L.S.V. Contextualização da Arte, da Técnica e da Tecnologia no Design Industrial: Um Estudo de Caso na Empresa Eletrolux /Curitiba-PR. Monografia. Programa de Pós Graduação CEFET- PR. 1997.

JONES, J. C.. Design methods. Londres : John Willey and Co., 1963.

KRIPPENDORFF, Klaus. Content analysis: an introduction to its methodology. 2. ed. Thousand Oaks, Calif: Sage, 2004. $413 \mathrm{p}$.

LAKATOS, Eva Maria; MARCONI, Marina de Andrade. Metodologia do Trabalho Científico: procedimentos básicos, pesquisa bibliográfica, projeto e relatório, publicações e trabalhos científicos. São Paulo: Atlas, 2002.

LAWSON, Bryan. Como arquitetos e designers pensam. Tradução de Maria Beatriz Medina. São Paulo: Oficina de Textos, 2011.

LÖBACH, Bernd. Design Industrial: Bases Para a Configuração dos Produtos Industriais. São Paulo: Edgard Blucher, 2001.

LOSCHIAVO SANTOS, Maria Cecília dos. Móvel Moderno no Brasil. 2. ed. São Paulo: Olhares, 2015.

LOSCHIAVO SANTOS, Maria Cecilia Loschiavo dos. Jorge Zalszupin: Design Moderno No Brasil. São Paulo: Olhares Editora, 2014.

MORAES, Dijon de. Metaprojeto como modelo projetual. In: MORAES, Dijon de; DIAS, Regina Álvares; CONSELHO, Rosemary Bom (Org.). Método: Cadernos de estudos avançados em design. Barbacena, MG: EDUEMG, 2011. Cap. 2. p. 35-52.

MORAES, Dijon de; DIAS, Regina Álvares; CONSELHO, Rosemary Bom (Org.). Cadernos de estudos avançados em design: Método. Barbacena: EDUEMG, 2011. Cap. 4. p. 67-86.

MOURA, Mônica. Design: objetos de fazer pensar: 23ํPêmio Design MCB. Dobras, São Paulo, v. 4, n. 8, p.47-50, 2010. Semestral.

MUNARI, Bruno. Das coisas nascem coisas. São Paulo: Martins Fontes, 1998.

NEVES, André et al. XDM: Métodos Extensíveis de Design. In: CONGRESSO BRASILEIRO DE PESQUISA E DESENVOLVIMENTO EM DESIGN, 8., 2008, São Paulo: AEND|BRASIL, 2008. p. 249 - 259

NIEMEYER, Lucy. Design e humanismo: por um novo modelo. In: MORAES, Dijon de; CELASCHI, Flaviano (Org.). Cadernos de Estudos Avançados em Design: humanismo. v. 7. Barbacena: EdUEMG, 2013, p. 71-78.

NIEMEYER, Lucy. Design no Brasil: origens e instalação. 2. ed. Rio de Janeiro: 2ab, 1998. 126 p.

PAPANEK, Victor. Design for the real world: human ecology and social change. 2. ed. London: Thames and Hudson, 1985.

PAZMINO, Ana Veronica. Como se Cria: 40 Métodos para Design de Produtos. São Paulo: Blücher, 2015.

PHILLIPS, Peter L. Briefing: a gestão do projeto de Design. São Paulo: Blucher, 2008. 
PIÑÓN, Helio. Teoria do projeto. Porto Alegre: Livraria do Arquiteto, 2006.

PONTE, Raquel; NIEMEYER, Lucy. Criatividade no processo de design: do projeto ao uso de produtos. Arcos Design, Rio de Janeiro, v. ,7 n. 1, p. 102-114, jul. 2013.

POYNOR, Rick. Abaixo as regras: design gráfico e pós-modernismo. Porto Alegre: Bookman, 2010. 192 p. Tradução: Mariana Bandarra.

ROZENFELD, Herique et al. Gestão do Desenvolvimento de Produtos: Uma referência para a melhoria do processo. São Paulo: Saraiva, 2006.

SCHNEIDER, Beat. Design - uma introdução. O design no contexto social, cultural e econômico. São Paulo: Ed. Blucher, 2010.

SCHÖN, Donald A.. Educando o Profissional Reflexivo: um novo design para o ensino e a aprendizagem. Porto Alegre: Artmed, 2000. 256 p.

SILVA, Maria Angélica Covelo; SOUZA, Roberto de. Gestão do Processo de Projeto de Edificações. São Paulo: O Nome da Rosa, 2003. 181 p.

SILVA, Regina Celia Barbosa da. Arquitetura e design: os conteúdos que acercam seus programas de ensino. 2009. 193 f. Dissertação (Mestrado) - Curso de Arquitetura e Urbanismo, Universidade São Judas Tadeu, São Paulo, 2009

SNYDER, James C.; CATANESE, Anthony. Introdução à Arquitetura. Rio de Janeiro: Campus, 1984.

SOUZA, Aline Teixeira de; MENEZES, Marizilda dos Santos. DIRETRIZES PROJETUAIS E O EMPREGO DAS TENDÊNCIAS: O DESIGN DE MÓVEIS RESIDENCIAIS NO PÓLO DE ARAPONGAS/PR. Educação Gráfica, Bauru, v. 14, n. 01, p.03-20, fev. 2010. Disponível em: <http://www.educacaografica.inf.br/artigos/diretrizes-projetuais-e-oemprego-das-tendencias-o-design-de-moveis-residenciais-no-polo-de-arapongaspr>. Acesso em: 13 abr. 2015.

VOORDT, Theo J.M. van Der; VAN WEGEN, Herman B.R.. Arquitetura sob o olhar do usuário: programa de necessidades, projeto e avaliação de edificações. São Paulo: Oficina de Textos, 2013. 237 p. Tradução de: Maria Beatriz Medina.

\section{NOTAS}

1 Pesquisa de mestrado intitulada "Investigação sobre aproximações e singularidades nos métodos e processos de projeto em arquitetura e design: da teoria à prática dos escritórios”, desenvolvida no PPGAU - FAUeD - UFU (Programa de Pós Graduação em Arquitetura e Urbanismo na Faculdade de Arquitetura Urbanismo e Design da Universidade Federal de Uberlândia.

2 Os escritórios pesquisados assinaram um "Termo de Consentimento Livre e Esclarecimento" convidando o profissional e esclarecendo o intuito da pesquisa o qual, também autorizava a divulgação do nome do escritório. Porém como o foco da pesquisa são os métodos e processo de projeto, os nomes destes foram preservados e, estes foram denominados de Escritórios de Arquitetura 1 e Escritório de Arquitetura 2; Escritórios de Design 1 e Escritórios de Design 2; Escritório de Arquitetura e Design.

${ }^{3} \mathrm{O}$ arquiteto é mestre em história e fundamentos da arquitetura e urbanismo pela FAUUSP, São Paulo (2017). Graduou-se em arquitetura e urbanismo pela Escola da Cidade (2010). Instituição onde atuou como professor-assistente (2011-2014). Colaborou com diversos escritórios de arquitetura de São Paulo e desde 2014 mantém escritório próprio, no qual atua sozinho.

${ }^{4}$ O responsável pelo escritório graduou-se em Arquitetura e Urbanismo pela Faculdade de Arquitetura e Urbanismo e Design - FAUeD, na Universidade Federal de Uberlândia (2002). Instituição onde atuou como professor substituto (2009-2011).

5 O responsável pelo escritório cursou Design de Produto na UFRJ, Rio de Janeiro (1997), foi Coordenador do Centro Design Rio (2004-2006). Participou de um levantamento sobre a cultura do mobiliário doméstico realizado pela CNI, criando coleções de móveis para empresas do cluster de móveis Ubá / MG, a pedido do Sebrae (2010 e 2012). Atuou como jurado nas seguintes competições de design: Feira Salão Design Casa Brasil e Tok \& Stok para estudantes (2009), Feira Salão Design Movelsul (2010), Masisa Company (2010) e Movelpar Feira (2011). Dirigiu o workshop de projeto Acre, Made in Amazonia (2013), resultando cinco linhas de mobiliário de design contemporâneo, com as quais participou da Milano Design Week (2014).

${ }^{6}$ O responsável do escritório nasceu em 1974 e, graduou-se em Desenho Industrial pela Escola de Belas Artes da UFRJ em 1997. Ainda na universidade, envolveu-se na criação da primeira revista sobre design da internet brasileira: a "Novo Conceito". Iniciou o seu trabalho como designer autônomo em 2002, projetando principalmente peças de mobiliário e decoração, dentre as quais várias apresentam premiações.

${ }^{7} \mathrm{O}$ arquiteto, fundador do escritório nasceu em 1989, se formou em Arquitetura e Urbanismo pelo Centro Universitário Belas Artes, SP em 2012, também tem especialização em iluminação na Escola Superior de Design e Engenharia de Barcelona. O escritório comercializa e distribuir seus mobiliário através de plataformas de Design aberto - Plataforma de distribuição e venda de mobiliário para o mundo todo), como a plataforma OpenDesk (Primeira plataforma de produção local de mobiliário com design aberto do mundo. e a Mono Design (Plataforma brasileira utilizada para venda e download gratuito dos projetos de mobiliário desenvolvidos pelo escritório).

NOTA DO EDITOR ( ${ }^{*}$ ) O conteúdo do artigo e as imagens nele publicadas são de responsabilidade do(s) autor(es). 